\title{
KARAKTERISTIK PENDERITA KANKER TIROID DI BAGIAN BEDAH ONKOLOGI DI RUMAH SAKIT UMUM DAERAH DR. H. ABDUL MOELOEK PROVINSI LAMPUNG TAHUN 2017-2019
}

\author{
Andi Siswandi ${ }^{1}$, Neno Fitriyani ${ }^{2}$, Ika Artini ${ }^{3}$, Krista Monitira ${ }^{4}$ \\ ${ }^{1}$ Departemen Bedah Rumah Sakit DKT \\ ${ }^{2}$ Departemen Ilmu Kesehatan Masyarakat Fakultas Kedokteran Universitas \\ Malahayati \\ ${ }^{3}$ Departemen Farmakologi Fakultas Kedokteran Universitas Malahayati \\ ${ }^{4}$ Program Studi Kedokteran Fakultas Kedokteran Universitas Malahayati
}

[email korespondensi: krista.180798@gmail.com]

\begin{abstract}
Characteristics Of Tiroid Cancer Patients In Oncological Surgery Part In The Regional General Hospital, DR. H. ABDUL MOELOEK Lampung Province In 2017-2019. Thyroid cancer is the most common endocrine gland malignancy, which is about $95 \%$ of all malignancies in the endocrine system. Every year around $7 \%$ an increase in the incidence of thyroid cancer, an increased incidence faster than other types of solid cancer, Based on data at Dharmais Cancer Hospital over the past 4 years from 2010-2013 in Indonesia, cancer incidence Thyroid ranks 4th from the most common cancer incidence.To determine the characteristics of thyroid cancer sufferers in the oncology surgery department at the regional general hospital DR. H. ABDUL MOELOEK of Lampung Province in 2017-2019. This type of research is a descriptive study with a cross-sectional study design with purposive sampling technique in thyroid cancer patients in the regional general hospital DR. $\mathrm{H}$. ABDUL MOELOEK of Lampung Province in 2017-2019. In this study the highest sex distribution in thyroid cancer patients was found in women, 44 patients $(84.6 \%)$. $53.8 \%)$. The main diagnosis that is most often found is papillary with 30 patients $(57.7 \%)$. The most common place of residence is 48 mountains $(88.5 \%)$.In this study the characteristics of thyroid cancer sufferers based on sex, age, main diagnosis, and residence.Suggestion: it is hoped that researchers will be able to analyze hormonal factors in thyroid cancer patients
\end{abstract}

Keywords: Characteristics, ThyroidCancer, RSUD DR. H. Abdul Moeloek

\begin{abstract}
Abstrak: Karakteristik Penderita Kanker Tiroid di Bagian Bedah Onkologi Di Rumah Sakit Umum Daerah DR. H. ABDUL MOELOEK Provinsi Lampung Tahun 2017-2019. Kanker tiroid adalah keganasan kelenjar endokrin yang paling sering ditemukan yaitu sekitar $95 \%$ dari semua keganasan pada sistem endokrin. setiap tahunnya sekitar $7 \%$ terjadi peningkatan insidensi kanker tiroid, peningkatan insiden lebih cepat dibandingkan kanker solid jenis lain Menurut data di RS Kanker Dharmais selama 4 tahun terakhir terhitung 2010-2013 di Indonesia, kejadian kanker tiroid menempati urutan ke 4 dari kejadian kanker yang tersering. Untuk mengetahui Karakteristik Penderita Kanker Tiroid di Bagian Bedah Onkologi Di Rumah Sakit Umum Daerah DR. H. ABDUL MOELOEK Provinsi Lampung Tahun 2017-2019.Jenis penelitian yang digunakan adalah penelitian Deskriptif dengan desain Cross Sectional Study dengan teknik pengambilan sampel Purposive Sampling pada pasien kanker tiroid di rumah sakit umum daerah DR. H. ABDUL MOELOEK Provinsi Lampung Tahun 2017-2019.Pada penelitian ini didapatkan distribusi jenis kelamin pada pasien kanker tiroid paling banyak pada perempuan yaitu 44 pasien $(84,6 \%)$. Populasi kelompok usia pada pasien kanker tiroid paling banyak pada kelompok usia (40-60 tahun) dengan jumlah 28 orang $(53,8 \%)$. Diagnosis utama yang paling sering ditemukan adalah papilar dengan jumlah 30 pasien $(57,7 \%)$.Tempat tinggal yang paling banyak di temukan adalah bukan pegunungan sebanyak 48 pasien $(88,5 \%)$.Pada penelitian ini didapatkan karakteristik penderita kanker tiroid
\end{abstract}


berdasarkan jenis kelamin, usia, diagnosis utama, dan tempat tinggal. Diharapkan peneliti senajutnya dapat menganalisis faktor hormonal pada pasien kanker tiroid

Kata kunci :Karakteristik, Kanker Tiroid, RSUD DR. H. Abdul Moeloek

\section{PENDAHULUAN}

Kanker tiroid adalah keganasan kelenjar endokrin yang paling sering ditemukan yaitu sekitar $95 \%$ dari semua keganasan pada sistem endokrin.Setiap tahunnya sekitar 7\% terjadi peningkatan insidensi kanker tiroid, peningkatan insiden lebih cepat dibandingkan kanker solid jenis lain. (Putri, Khambri\& Rusjdi, 2017). Angka kejadian karsinoma tiroid menurut data American Cancer Society diperkirakan mencapai 44.670 kasus baru pada tahun 2010. Dan data terbaru dari penderita kanker tiroid di Amerika Serikat pada tahun 2014 berjumlah 62.980 kasus baru dan terdapat 1.890 kematian diakibatkan karena kanker tiroid, kejadian kanker tiroid pada lakilaki dan perempuan dengan perbandingan 1:3. Dengan kata lain kanker tiroid lebih sering terjadi pada perempuan. Umumnya, (Parura, Pontoh, \& Merung, 2016).

Beradasarkan data di RS Kanker Dharmais selama 4 tahun terakhir terhitung 2010-2013 di Indonesia, kejadian kanker tiroid menempati urutan ke 4 dari kanker yang tersering terjadi pada perempuan dengan berdasarkan jumlah kasus baru 85 pasien di tahun 2010, 99 pasien di tahun 2011, 117 pasien di tahun 2012 dan 147 pasien di tahun 2013. Sedangkan berdasarkan perkiraan jumlah kematian akibat kanker tiroid di RS Dharmais cenderung meningkat di tahun 2012 yaitu, 12 kasus kematian dari 7 kasus kematian di tahun 2010 (Kemenkes, 2015).Di Provinsi Lampung berdasarkan data penelitian sebelumnya di RSUD DR H. ABDUL MOELOEK Provinsi Lampung terdapat pasien kanker tiroid periode 2013-2015 sebanyak 68 penderita kanker tiroid. Tersering terjadi pada perempuan yaitu 55 penderita dengan jumlah usia terbanyak yang terkena kanker tiroid 31-40 tahun yaitu 24 penderita (Kusuma, 2017).

Berdasarkan hasil penelitian dilakukan di bagian Rekam Medik dan Patologi Anatomi RSUP Prof. DR Kandou Manado didapatkan data penderita kanker tiroid periode Juli 2013 -Juni 2016 adalah sebanyak 62 penderita, pada perempuan sebanyak 39 orang $(62,9 \%)$ sedangkan laki-laki sebanyak 23 orang $(37,1 \%)$.

Berdasarkan umur, penderita kanker tiroid paling banyak terjadi pada pasien golongan umur 40-60 tahun sebnyak 27 pasien dan $>60$ tahun sebanyak 23 pasien. Disusul golongan umur 20-40 ahun sebanyak 11 pasien kemudian golongan $<20$ tahun sebanyak 1 pasien (Parura, Pontoh, \& Merung, 2016). Kejadian kanker tiroid berdasarkan tempat tinggal ditemukan 102 kasus kanker tiroid, dimana 32 kasus bertempat tinggal di daerah berseiko defisiensi yodium dan 70 kasus bertempat tinggal di daerah tidak berisiko defiseinsi yodium. (Putri, Khambri, \& Rusjdi, 2017).

Berdasarkan gambaran

histopatologinya kanker tiroid dibagi menjadi tipe papiler, folikuler, meduler dan anaplastik. Dankejadiannyapun bervariasi, yakni: tipe papiler $60-80 \%$, tipe folikuler $10-27,5 \%$, tipe medular 3$10 \%$ dan tipe anaplastik 3-8\%. Dari segi agresifitas, pada tipe anaplastik memiliki prognosis paling buruk, dimana angka kematiannya hampir $100 \%$, disusul oleh tipe meduler dengan angka harapan hidup dalam 10 tahun sebesar $65 \%$. Tipe folikuler dan papiler prognosisnya lebih baik, angka kematian dalam 30 tahun pertama pada tipe folikuler sebesar $15 \%$ dan papiler $6 \%$. (Putri, Khambri, \& Rusjdi, 2017). 


\section{METODE}

Jenis penelitian yang digunakan adalah penelitian Deskriptif yaitu penelitian yang diarahkan untuk mendeskripsikan atau menguraikan suatu kejadian (Notoatmodjo, 2012). Dengan desain Cross Sectional Study yaitu penelitian yang variabel nya diukur dalam satu waktu (Sastroasmoromoro s. dan Ismael s. 2011). Penelitian ini dilaksanakan di RSUD DR. H. ABDUL MOELOEK Provinsi Lampung.Populasi dalam penelitian ini adalah semua data pasien kanker tiroid di di RSUD DR. H. ABDUL MOELOEK Provinsi Lampung tahun 20172019.Dengan jumlah populasi sebanyak 60 orang.

Teknik pengambilan sampel yang digunkan adalah purposive sampling dimana seluruh sampel dalam penelitian ini dieliti yaitu sebanyak 52 pasien. Dengan variabel, usia, jenis kelamin, jenis kanker, dan tempat tinggal. Analisis yang digunakan dalam penelitian ini adalah analisis univariat.

\section{Kriteria inklusi}

a. Semua data rekam medik lengkap pasien kanker tiroid di RSUD DR. H. ABDUL MOELOEK Provinsi Lampung tahun 20017-2019.

b. Pembesaran tiroid tanpa penyakit penyerta seperti DM, hipetensi dan kanker sebelum nya.

\section{Kriteria eklusi}

a. Lembar rekam medik tidak lengkap atau rusak.

b. Lembar rekam medik tidak dapat dibaca

c. Pembesaran tiroid selain kanker seperti grave disease, struma nodusa dan tiroiditis.

\section{HASIL}

\section{Analisis Univariat}

Berdasarkan tabel 1, dapat diketahui bahwa jumlah pasien kanker tiroid pada tahun 2017 sebanyak 11 pasien $(21 \%)$ menempati urutan terendah, dan 2018 sebanyak 23 pasien (44\%) menempati urutan tertinggi, lalu pada tahun 2019 menempati urutan kedua sebanyak 18 pasien $(35 \%)$.

Tabel 1. Distribusi Frekuensi Kanker Tiroid Berdasarkan Tahun

\begin{tabular}{ccc}
\hline Tahun & $\begin{array}{c}\text { Frekuensi } \\
(\mathbf{n})\end{array}$ & $\begin{array}{c}\text { Presentase } \\
(\mathbf{\%})\end{array}$ \\
\hline 2017 & 11 & $21 \%$ \\
2018 & 23 & $44 \%$ \\
2019 & 18 & $35 \%$ \\
\hline Jumlah & 52 & $100 \%$ \\
\hline
\end{tabular}

Berdasarkan tabel 2, maka dapat diketahui bahwa dari 52 responden kanker tiroid didapatkankategori frekuensi umur tertinggi yaitu pada kategori umur (40-60 tahun) dengan jumlah 28 orang $(53,8 \%)$, dan kategori dengan tingkat frekuensi umur terendah yaitu pada kategori ( $<20$ tahun) yaitu hanya sebesar 1 orang $(1,9 \%)$.

Tabel 2.Distribusi Frekuensi Kanker Tiroid Berdasarkan Usia Pasien

\begin{tabular}{ccc}
\hline Usia & $\begin{array}{c}\text { Frekuensi } \\
(\mathbf{n})\end{array}$ & $\begin{array}{c}\text { Presentase } \\
(\%)\end{array}$ \\
\hline$<20$ & 1 & $1,9 \%$ \\
$20-40$ & 16 & $30,8 \%$ \\
$40-60$ & 28 & $53,8 \%$ \\
$>60$ & 7 & $13,5 \%$ \\
\hline Jumlah & 52 & $100 \%$ \\
\hline
\end{tabular}

Berdasarkan tabel 3, dapat diketahui bahwa jenis kelamin pasien yang terkena kanker tiroid pada laki-laki sebanyak 8 pasien $(15,4 \%)$, dan pada perempuan sebanyak 44 pasien $(84,6 \%)$.

Tabel 3. Distribusi Frekuensi Kanker Tiroid Berdasarkan Jenis Kelamin Pasien

\begin{tabular}{ccc}
\hline $\begin{array}{c}\text { Jenis } \\
\text { kelamin }\end{array}$ & $\begin{array}{c}\text { Frekuensi } \\
(\mathbf{n})\end{array}$ & $\begin{array}{c}\text { Presentase } \\
(\%)\end{array}$ \\
\hline Laki-laki & 8 & $15,4 \%$ \\
Perempuan & 44 & $84,6 \%$ \\
\hline Jumlah & 52 & $100 \%$ \\
\hline
\end{tabular}


Berdasarkan gambar 4, maka dapat diketahui bahwa dari 52 responden kanker tiroid didapatkan kategori frekuensi jenis kanker tertinggi yaitu pada jenis papilar dengan jumlah 30 pasien $(57,7 \%$, dan kategori dengan tingkat frekuensi jenis kanker terendah yaitu pada kategori medular dan anaplasik yaitu hanya sebesar 4 pasien $7,7 \%$.

Tabel 4. Distribusi Frekuensi Kanker Tiroid Berdasarkan Jenis Kanker Tiroid

\begin{tabular}{lcc}
\hline $\begin{array}{c}\text { Jenis } \\
\text { kanker }\end{array}$ & $\begin{array}{c}\text { Frekuensi } \\
(\mathbf{n})\end{array}$ & $\begin{array}{c}\text { Presentase } \\
(\%)\end{array}$ \\
\hline Papilar & 30 & $57,7 \%$ \\
Folikular & 14 & $26,9 \%$ \\
Medular & 4 & $7,7 \%$ \\
Anaplastik & 4 & $7,7 \%$ \\
\hline Jumlah & 52 & $100 \%$ \\
\hline
\end{tabular}

Berdasarkan tabel 5, dapat diketahui bahwa tempat tinggal pasien yang terkena kanker tiroid pada daerah pegunungan sebanyak 6 pasien(11,5\%), dan pada pada daerah bukan pegunungan sebanyak 48 pasien $(88,5 \%)$.

Tabel 5. Distribusi Frekuensi Kanker Tiroid Berdasarkan Tempat Tinggal Pasien

\begin{tabular}{ccc}
\hline $\begin{array}{c}\text { Tempat } \\
\text { Tinggal }\end{array}$ & $\begin{array}{c}\text { Frekuensi } \\
(\mathbf{n})\end{array}$ & $\begin{array}{c}\text { Presentase } \\
(\mathbf{\%})\end{array}$ \\
\hline $\begin{array}{c}\text { Bukan } \\
\text { Pegunungan }\end{array}$ & 48 & $88,5 \%$ \\
Pegunungan & 6 & $11,5 \%$ \\
\hline Jumlah & 52 & $100 \%$ \\
\hline
\end{tabular}

\section{PEMBAHASAN}

Berdasarkan tabel 1, dapat diketahui bahwa jumlah pasien kanker tiroid terbanyak pada tahun 2018 sebanyak 23 pasien (44\%), lalu pada tahun 2019 sebanyak 18 pasien (35\%), dan yang terendah pada tahun 2017 sebanyak 11 pasien(21\%).Berdasarkan tabel 2, maka dapat diketahui bahwa dari 52 responden kanker tiroid didapatkan kategori frekuensi umur tertinggi yaitu pada kategori umur (40-
60 tahun) dengan jumlah 28 orang $(53,8 \%)$, dan kategori dengan tingkat frekuensi umur terendah yaitu pada kategori (< 20 tahun) yaitu hanya sebesar 1 orang $(1,9 \%)$. Hal ini sesuai dengan penelitian Parura, Pontoh, \& Merung, tahun 2016 yang dilakukan di bagian Rekam Medik dan Patologi Anatomi RSUP Prof. DR Kandou Manado didapatkan data berdasarkan umur, penderita kanker tiroid paling banyak terjadi pada pasien golongan umur 4060 tahun sebnyak 27 pasien dan $>60$ tahun sebanyak 23 pasien. Disusul golongan umur 20-40 ahun sebanyak 11 pasien kemudian golongan $<20$ tahun sebanyak 1 pasien. Berdasarkan tabel 3, dapat diketahui bahwa jenis kelamin pasien yang terkena kanker tiroid pada laki-laki sebanyak 8 pasien $(15,4 \%)$, dan pada perempuan sebanyak 44 pasien $(84,6 \%)$.

$\mathrm{Hal}$ ini sesuai dengan penelitian Parura, Pontoh, \& Merung, tahun 2016 yang dilakukan di bagian Rekam Medik dan Patologi Anatomi RSUP Prof. DR Kandou Manado didapatkan data penderita kanker tiroid periode Juli 2013 -Juni 2016 adalah sebanyak 62 penderita, pada perempuan sebanyak 39 orang $(62,9 \%)$ sedangkan laki-laki sebanyak 23 orang $(37,1 \%)$. Kejadiannya pun bervariasi, yakni: tipe papiler $60-80 \%$, tipe folikuler $10-$ $27,5 \%$, tipe medular $3-10 \%$ dan tipe anaplastik 3-8\%. Berdasarkan tabel 5, dapat diketahui bahwa tempat tinggal pasien yang terkena kanker tiroid pada daerah pegunungan sebanyak 6 pasien $(11,5 \%)$, dan pada pada daerah bukan pegunungan sebanyak 48 pasien $(88,5 \%)$. Hal ini sesuai dengan penelitian Putri, Khambri, \& Rusjdi, tahun 2017 kejadian kanker tiroid berdasarkan tempat tinggal ditemukan 102 kasus kanker tiroid, dimana 32 kasus bertempat tinggal di daerah berisiko defisiensi yodium dan 70 kasus bertempat tinggal di daerah tidak berisiko defiseinsi yodium.

\section{KESIMPULAN}

1. Data jumlah pasien kanker terbanyak pada tahun 2018 sebanyak 23 pasien $(44 \%)$, lalu 
pada tahun 2019 sebanyak 18 pasien $(35 \%)$, dan yang terendah pada tahun 2017 sebanyak 11 pasien (21\%).

2. Distribusi frekuensi kanker tiroid berdasarkan usia, tersering di temukan pada kelompok usia 40-60 ahun sebanyak 28 pasien $(53,8 \%)$ dan kelompok usia terendah < 20tahun yaitu hanya sebesar 1 orang $(1,9 \%)$

3. Distribusi frekuensi kanker tiroid berdasarkan jenis kelamin, tersering terjadi pada wanita sebanyak 44 pasien $(84,6 \%)$, lalu pada laki-laki sebanyak 8 pasien $(15,4 \%)$

4. Distribusi frekuensi kanker tiroid berdasarkan tempat tinggal tersering pada daerah bukan pegunungan sebanyak 48 pasien $(88,5 \%)$, lalu pada daerah pegunungan sebanyak 6 pasien $(11,5 \%)$.

5. Distribusi frekuensi kanker tiroid berdasarkan

terbanyak histopatologis

pada kanker jenis papilar 30 pasien $(57,7 \%)$, dan kategori dengan tingkat frekuensi jenis kanker terendah yaitu pada kategori medular dan anaplastik yaitu hanya sebesar 4 pasien $7,7 \%$.

\section{SARAN}

Pemerintah diharapkan menambah literatur atau referensi mengenai penelitian yang terkait kanker tiroid, Sehingga nanti institusi pemerintah akan mencantumkan frekuensi kejadian kanker tiroid kedalam data riskesdas terbaru, dan diharapkan dapat menjadi acuan data yang nantinya dipakai untuk skrining kanker karena sebelumnya belum dapat dicegah.

Peneliti selanjutnya diharapkan dapat dilakukan penenlitian lanjutan mengenai kanker tiroid agar nantinya dapat dijadikan sebagai sarana edukasi masyarakat dan kepentingan pendidikan. Pada penelitian selanjutnya, diharapkan untuk meneliti faktor lain yang kiranya dapat mempengaruhi kanker tiroid, sebagai contoh yaitu faktor hormonal yang mana dalam penelitian ini tidak dilakukan.

\section{DAFTAR PUSTAKA}

Kementrian Kesehatan RI.(2015). Pusat Data Dan Informasi Kementrian Kesehatan RI Tentang Hari Kanker Sedunia.Jakarta :KEMENKES RI.

Kusuma.(2017). Hubungan umur dan jenis kelamin dengan kejadian karsinoma tiroid di Rumah Sakit Umum Daerah DR. H. ABDUL MOELOEK Bandar Lampung tahun 2014-2016. [skripsi]Lampung :UniversitasMalahayati.

Notoatmodjo, S. (2012).Metodologi Penelitian Kesehatan.Jakarta : Rineka Cipta, 115.

Parura Y. Pontoh V. \& Merung M.(2016).Pola Kanker Tiroid Periode juli 2013 - juni 2016 di RSUP Prof. DR. R.D. Kandou Manado.Jurnal e-Clinic (eCl)(4).

Putri, E., Khambri, D., \& Rusjdi, S. R. (2017). Hubungan daerah tempat tinggal dengan gambaran histopatologi karsinoma tiroid pada masyarakat sumatra barat.Jurnal Kesehatan Andalas.171-174.

Sastroasmoro, S., dan Ismael, S. (2011).Dasar-Dasar Metodologi Penelitian Klinis. Jakarta: Sagung Seto,108-109\&177. 